\title{
RPE65 Is Present in Human Green/Red Cones and Promotes Photopigment Regeneration in an In Vitro Cone Cell Model
}

\author{
Peter H. Tang, ${ }^{1}$ Mona C. Buhusi, ${ }^{1}$ Jian-Xing Ma, ${ }^{3}$ and Rosalie K. Crouch ${ }^{1,2}$ \\ Departments of ${ }^{1}$ Neuroscience and ${ }^{2}$ Ophthalmology, Medical University of South Carolina, Charleston, South Carolina 29425 , and ${ }^{3}$ Department of \\ Physiology, University of Oklahoma Health Sciences Center, Oklahoma City, Oklahoma 73104
}

RPE65 is an abundantly expressed protein within the retinal pigment epithelium (RPE) of the eye that is required for retinoid metabolism to support vision. Its genetic mutations are linked to the congenital disease Leber congenital amaurosis Type 2 (LCA2) characterized by the early onset of central vision loss. Current gene therapy trials have targeted restoration of functional RPE65 within the RPE of these patients with some success. Recent data show that RPE65 is also present within mouse cones to promote function. In this study, we evaluated the presence of RPE65 in human cones and investigated its potential mechanism for supporting cone function in the $661 \mathrm{~W}$ cone cell line. We found that RPE65 was selectively expressed in human green/red cones but absent from blue cones and mediated ester hydrolysis for photopigment synthesis in vitro. These data suggest that cone RPE65 supports human diurnal vision, potentially enhancing our strategies for treating LCA2.

\section{Introduction}

Visual function is dependent on light detection by rod and cone photoreceptors through photopigments formed from the chromophore 11-cis-retinyl-aldehyde (RAL) bound to opsin G-protein-coupled receptors. Human cones mediate daytime color vision through one of three forms of opsins to detect blue (short-wavelength; S), green (mid-wavelength; M), or red (longwavelength; L) light. When light bleaches the photopigment, 11cis-RAL isomerizes to the all-trans conformation, triggering the phototransduction cascade. Finally, all-trans-RAL disassociates from the opsin and is reduced to all-trans-retinyl-alcohol (ROL) by retinol dehydrogenases (RDHs). To regenerate photopigment, all-trans-ROL is converted back to 11-cis-RAL through an enzymatic process called the visual cycle (Travis et al., 2007) (Fig. 1).

RPE65 protein plays a critical role in 11-cis-RAL synthesis within the eye. It is essential for all-trans- to 11-cis-retinoid isomerization (Jin et al., 2005; Moiseyev et al., 2005; Redmond et al., 2005), established through $R p e 65^{-/-}$mouse studies in which

Received Aug. 18, 2011; revised 0ct. 31, 2011; accepted Nov. 3, 2011.

Author contributions:P.H.T., M.C.B., and R.K.C. designed research; P.H.T. and M.C.B. performed research; P.H.T., M.C.B., J.-X.M., and R.K.C. contributed unpublished reagents/analytic tools; P.H.T., M.C.B., J.-X.M., and R.K.C. analyzed data; P.H.T., M.C.B., and R.K.C. wrote the paper.

This study was supported in part by National Institutes of Health Grants R01 EY04939 (R.K.C.), R01 EY012231 (J.X.M.), and C06 RR015455 (Medical University of South Carolina), Foundation Fighting Blindness (R.K.C.), and an unrestricted grant (Department of Ophthalmology, Medical University of South Carolina) from Research to Prevent Blindness (RPB), the RPB Senior Scientific Investigator Award (R.K.C.), and the RPB Medical Student Research Fellowship (P.H.T.). We thank Luanna Bartholomew, Jie Fan, Patrice Goletz, Peter Kalivas, Masahiro Kono, Yiannis Koutalos, Ryan Parker, Bärbel Rohrer (Medical University of South Carolina, Charleston, SC), Vladimir Kefalov (Washington University School of Medicine, St. Louis, M0), and Gennadiy Moiseyev (University of Oklahoma Health Sciences (enter, Oklahoma (ity, 0K) for technical assistance, discussions, and manuscript revisions.

The authors declare no competing financial interests.

Correspondence should be addressed to Rosalie K. Crouch, Storm Eye Institute, Medical University of South Carolina, 167 Ashley Avenue, Charleston, SC 29425. E-mail: crouchrk@musc.edu.

DOI:10.1523/JNEUROSCI.4265-11.2011

Copyright $\odot 2011$ the authors $\quad 0270-6474 / 11 / 3118618-09 \$ 15.00 / 0$
11-cis-RAL synthesis was blocked and the substrate, all-transretinyl-ester (RE), accumulated (Redmond et al., 1998). Furthermore, the lack of endogenous chromophore production caused early cone degeneration (Znoiko et al., 2005). Human RPE65 mutations underlie the congenital disease Leber congenital amaurosis Type 2 (LCA2), characterized by severe loss of vision, sensory nystagmus, amaurotic pupils, and absent signals on electroretinography (den Hollander et al., 2008). Because the RPE is classically accepted as the exclusive region within the eye in which RPE65 metabolizes retinoids, gene therapy trials have targeted this area with moderate rescue of visual function in LCA2 patients (Cideciyan, 2010).

An alternate visual cycle may exist within the vertebrate retina to support cone photopigment regeneration independent of the RPE (Wang and Kefalov, 2011) (Fig. 1). The unidentified isomerase is believed to localize within Müller glia (Das et al., 1992; Muniz et al., 2009; Wang et al., 2009; Wang and Kefalov, 2009), and 11-cis-ROL production may underlie its cone specificity because cones can oxidize 11-cis-ROL but rods cannot (Jones et al., 1989; Parker et al., 2011). Complete regeneration of cone photopigments necessitates both alternate and RPE visual cycles, in which the former is fast and promotes initial rapid dark adaptation and the latter is slow and is required to complete the process (Kolesnikov et al., 2011).

RPE65 may play a novel role within the alternate visual cycle. Evidence first arose from the discovery of mRNA in salamander cones (Ma et al., 1998) and the protein in mammalian cones through immunohistochemistry (IHC) (Znoiko et al., 2002). We recently localized RPE65 to the outer segment (OS) region of the mouse cone and found that mouse strains with lower amounts of cone RPE65 were less efficient at regenerating cone photopigment than those with higher levels (Tang et al., 2011).

The mechanism through which cone RPE65 operates is not understood. Furthermore, its relevance to human vision has not 


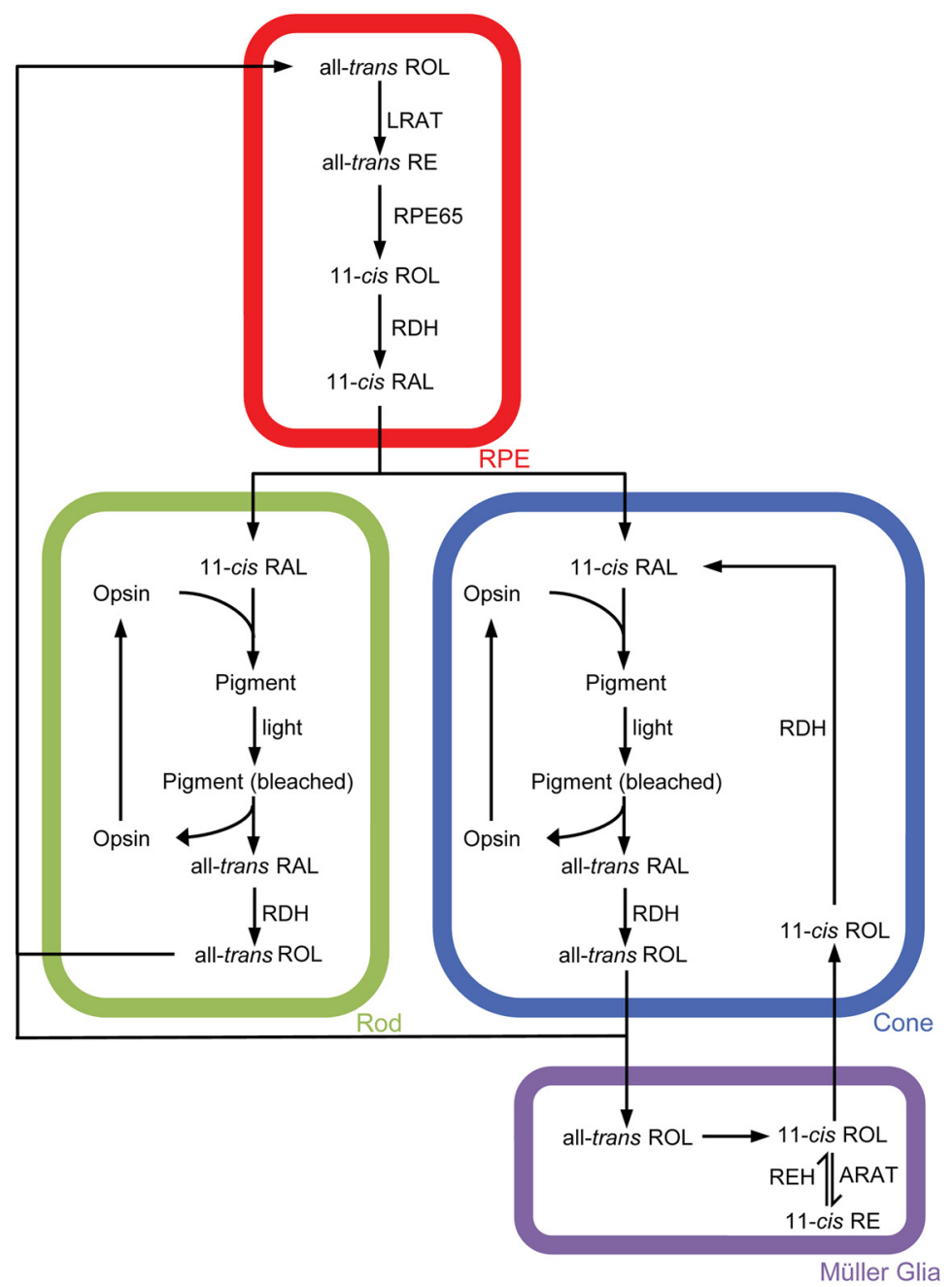

Figure 1. Schematic of the retinoid visual cycle. REH, Retinyl-ester hydrolase.

bit antibody has been described previously (Znoiko et al., 2002) and was used at a concentration of $2 \mu \mathrm{g} / \mathrm{ml}$ for IHC analysis and 0.2 $\mu \mathrm{g} / \mathrm{ml}$ for immunoblot analysis. The DALEED polyclonal rabbit antibody has been described previously (Moiseyev et al., 2008) and was used at a dilution of $2 \mu \mathrm{g} / \mathrm{ml}$ for IHC analysis and $0.2 \mu \mathrm{g} / \mathrm{ml}$ for immunoblot analysis. For the target epitope sequence of each antibody, see Table 1.

Other primary antibodies. The following antibodies were used: anti-S- and M/L-cone opsins goat polyclonal antibodies (Santa Cruz Biotechnology) at $2 \mu \mathrm{g} / \mathrm{ml}$ for IHC; anti-green fluorescent protein (GFP) FITC-conjugated polyclonal rabbit antibody (Invitrogen) at 2 $\mu \mathrm{g} / \mathrm{ml}$ for IHC; anti-human cone arrestin monoclonal 7G6 antibody generously provided by Wolfgang Baehr (University of Utah, Salt Lake City, UT) and used as described previously (Zhang et al., 2003); and anti-rod opsin 1D4 monoclonal antibody and anti- $\beta$-actin monoclonal mouse antibody (Sigma-Aldrich), used at 0.05 and $0.5 \mu \mathrm{g} / \mathrm{ml}$, respectively, for immunoblots.

Generation of monoclonal population of stable RPE65-expressing $661 \mathrm{~W}$ cells. The $661 \mathrm{~W}$ cell line was a generous gift from Muayyad R. AlUbaidi (University of Oklahoma, Oklahoma City, OK) and cultured according to previously published protocol (Tan et al., 2004). The mouse Rpe65 cDNA (accession number BC130028), encoding for the Leu450 variant, was obtained from Open Biosystems. The Rpe 65 cDNA was subcloned into pIRES-EGFP vector (Clontech), and the sequence was verified (Medical University of South Carolina Nucleic Acid Analysis Facility). For transfection, Lipofectamine 2000 reagent (Invitrogen) and Opti-MEM I reduced-serum medium (Invitrogen) were used per the instructions of the manufacturer. Afterward, cells were subjected

Table 1. Specificities of anti-RPE65 antibodies

\begin{tabular}{|c|c|c|c|}
\hline Antibody & Target epitope & Residues & Species homology \\
\hline \multirow[t]{3}{*}{ PETLET } & \multirow[t]{3}{*}{ NFITKVNPETLETIK } & \multirow[t]{3}{*}{$150-164$} & B: NFITKVNPETLETIK \\
\hline & & & M: NFITKINPETLETIK \\
\hline & & & H: NFITKINPETLETIK \\
\hline \multirow[t]{3}{*}{ DALEED } & \multirow[t]{3}{*}{ VSHPDALEEDDGVV } & \multirow[t]{3}{*}{$473-486$} & B: VSHPDALEEDDGVV \\
\hline & & & M: VSQPDALEEDDGVV \\
\hline & & & H: VSHPDALEEDDGVV \\
\hline
\end{tabular}

Two polyclonal anti-RPE65 antibodies targeting distant epitopes of RPE65 protein are used for immunohistochemistry analysis. B, Bovine; $M$, mouse; $H$, human.

been established. We addressed these issues in the current study through IHC analysis of cones from donor human eyes and characterization of retinoid metabolism in an in vitro cone model (661W cells) (Tan et al., 2004) that has been genetically modified to express RPE65.

\section{Materials and Methods}

Human tissue. Human eyes were obtained from three donors (ages 11, 21, and 85 years). The 11- and 21-year-old donor eyes were from male donors and were acquired from the National Disease Research Interchange with assistance from Zsolt Ablonczy (Medical University of South Carolina, Charleston, SC). The 85-year-old donor eyes were from a female donor and were acquired from the San Diego Eye Bank with assistance from Anne Hanneken (Scripps Research Institute, La Jolla, CA).

Anti-RPE65-specific primary antibodies. The PETLET polyclonal rab- to selection pressure using $1.5 \mathrm{mg} / \mathrm{ml} \mathrm{G418}$ antibiotic (Mediatech). Resistant clones were isolated by flow cytometry based on GFP fluorescence (Medical University of South Carolina Flow Cytometry Facility). As a control, $661 \mathrm{~W}$ cells were transfected with the pIRES-EGFP vector lacking Rpe65 cDNA. A group of the monoclonal Rpe65-transfected 661W cells were further transfected with a pcDNA3.1-hygro vector (Invitrogen) containing mouse rod opsin cDNA (accession number BC031766), obtained from Open Biosystems. A stable cell line expressing both RPE65 and rod opsin was generated through selection pressure using $1.5 \mathrm{mg} / \mathrm{ml}$ hygromycin (Thermo Fisher Scientific). For the duration of all experiments, transfected cells were cultured in selection media.

Immunoblot analysis. To prepare human RPE homogenates, the cornea and lens were removed, and the retina was dissected away from the remaining eyecup. The $\mathrm{RPE} /$ choroid was then peeled away from the sclera. Procedures for the preparation of cell lysates have been described previously (Tan et al., 2004). Samples were homogenized in 1\% SDS (Sigma-Aldrich) using sonication on ice $(3 \times, 10 \mathrm{~s}$ each), loaded onto $4-12 \%$ gradient gel (NuPAGE Bis-Tris; Invitrogen), and then transferred to nitrocellulose membrane; membranes were probed with the appropriate primary and secondary antibodies and then stripped and reprobed for $\beta$-actin. Bands were visualized with ECL imaging equipment (VersaDoc; Bio-Rad). The peroxidase-conjugated secondary antibodies used were goat anti-rabbit IgG and horse anti-mouse IgG ( $1 \mathrm{ng} / \mathrm{ml}$ concentration; Vector Laboratories).

Immunohistochemistry. To prepare human retina flat mounts, the retina was dissected away from the eyecup. The retina was then fixed in $4 \%$ paraformaldehyde (PFA) in $0.1 \mathrm{M}$ PBS at $\mathrm{pH} 7.4$ for $1.25 \mathrm{~h}$, at room 

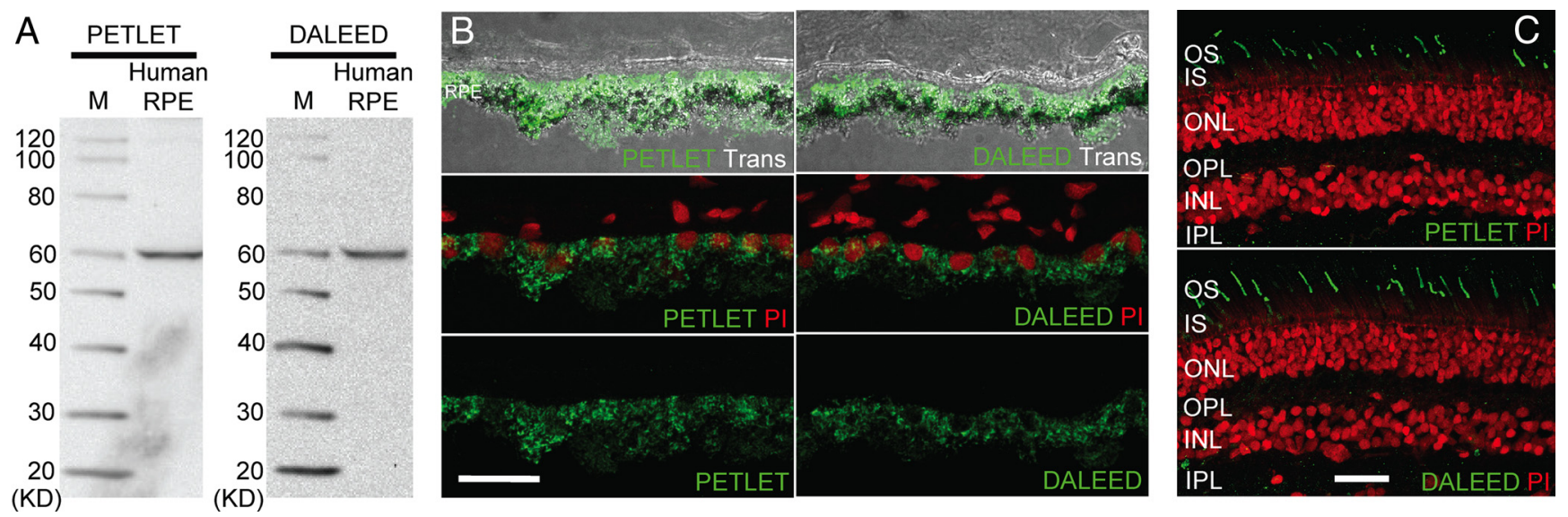

Figure 2. Anti-RPE65 antibodies detect RPE65 in human tissue samples. Immunoblot analysis using either PETLET or DALEED anti-RPE65 antibody detected a $\sim 63 \mathrm{kDa}$ major band corresponding to RPE65 in homogenates prepared from human $\operatorname{RPE}(\boldsymbol{A})$. Both antibodies also exhibited similar patterns of RPE65 staining in the $\operatorname{RPE}(\boldsymbol{B})$ and $0 S(\boldsymbol{C})$ regions of frozen sections prepared from human eyecups. Scale bars: $\boldsymbol{B}, 5 \mu \mathrm{m} ; \boldsymbol{C}, 15 \mu \mathrm{m}$. INL, Inner nuclear layer; IPL, inner plexiform layer; ONL, outer nuclear layer; OPL, outer plexiform layer; PI, propidium iodide; Trans, transmitted light; $\mathrm{M}$, marker.

temperature (RT) and then washed with PBS and blocked for $1 \mathrm{~h}$ at RT with a solution containing $1 \%$ bovine serum albumin (BSA; SigmaAldrich), $1 \%$ rabbit serum (Sigma-Aldrich), and $0.25 \%$ Triton X-100 (Sigma-Aldrich) in PBS. Retinas were then incubated overnight at $4^{\circ} \mathrm{C}$ with primary antibodies diluted in a solution containing $1 \%$ Tween 20 (Bio-Rad) and $1 \%$ Triton X-100 in PBS, washed, and then incubated with the appropriate secondary antibodies diluted in PBS for $2 \mathrm{~h}$ at RT. Retinas were coverslip mounted with Fluoromount-G (Southern Biotechnology Associates) for analysis by fluorescence microscopy (Axioplan II; Carl Zeiss) with appropriate filters.

To prepare frozen human eyecup sections, the cornea and lens were removed, and the remaining eyecup was bisected and fixed as described above. Eyecups were washed in PBS and incubated in 30\% sucrose in PBS overnight at $4^{\circ} \mathrm{C}$. Eyecups were embedded in OCT (Ted Pella), flash frozen in 2-methylbutane (Sigma-Aldrich) on dry ice, and cut with a cryomicrotome to produce $10 \mu \mathrm{m}$ sections; sections were processed for staining as described above. To visualize the nuclei and inner segments (ISs), sections were incubated with propidium iodide $(0.5 \mu \mathrm{g} / \mathrm{ml}$; SigmaAldrich) diluted in PBS for $2 \mathrm{~h}$ at RT. Images were acquired by confocal microscopy (Leica TCS SP5 AOBS Confocal Microscope System; Leica Microsystems).

To prepare $661 \mathrm{~W}$ cells for staining, cells were grown on chamber slides (Thermo Fisher Scientific) and fixed in freshly prepared 4\% PFA for 3 min. Slides were washed in PBS and processed for staining as described for retina flat mounts.

Retinoid delivery. All retinoids were handled under dim red light. 11cis-ROL was synthesized within our laboratory. All-trans-ROL was purchased from Sigma-Aldrich. 11-cis-ROL or all-trans-ROL was suspended in ethanol and mixed with PBS, $\mathrm{pH} 7.4$, containing $2 \%$ BSA as a carrier. Next, solution was mixed with fetal bovine serum and then combined with cell growth media for a final retinoid concentration of $10 \mu \mathrm{M}$ (Kanan et al., 2008) because 661W cells have been shown to tolerate this well for long-term incubation (Kanan et al., 2008), and our evaluation of cell survival after incubating across a range of concentrations $(0.25-20 \mu \mathrm{M})$ for $24 \mathrm{~h}$ in the dark confirmed these results. After incubation, cells were washed five times with $1 \mathrm{ml}$ of ice-cold PBS, collected with a cell scraper, and pelleted through centrifugation $(500 \times g, 3 \mathrm{~min})$, and retinoids were extracted. A concentration of $10 \mu \mathrm{M}$ of all-trans-ROL was used for the incubation media.

Retinoid extraction and HPLC analysis. The cell pellet was resuspended in $300 \mu \mathrm{l}$ of PBS and sonicated two times for $10 \mathrm{~s}$ each. Isolated retinas $(n=6)$ were homogenized in $200 \mu \mathrm{l}$ of PBS using a micro-tissue grinder. Methanol $(300 \mu \mathrm{l})$ and hydroxylamine $(60 \mu \mathrm{l}, 1 \mathrm{~mol} / \mathrm{L}$ in PBS) were added, and samples were vortexed ( $30 \mathrm{~s}$ ). After $5 \mathrm{~min}$ at $22^{\circ} \mathrm{C}$, methylene chloride $(300 \mu \mathrm{l})$ was added, and the samples were vortexed $(30 \mathrm{~s})$ and centrifuged $(14,000 \times g, 1 \mathrm{~min})$. The lower phase was separated, dried under argon, and dissolved in HPLC mobile phase (11.2\% ethyl acetate/ $2.0 \%$ dioxane $1.4 \%$ octanol in hexane, $90 \mathrm{ml}$ ). Separation of retinoids were performed using a Lichrosphere SI-60, $5 \mathrm{~mm}$ column (Alltech) and quantified by comparison of retention times and absorption properties with pure retinoid isomeric standards (Groenendijk et al., 1980). To calculate the amount of 11-cis-RE and all-trans-RE, the RE peak was collected from HPLC, dried under argon, and saponified according to a previously published protocol (Saari et al., 1993).

Statistical analysis. Differences in retinoid levels extracted from various groups of cells were tested using two-way ANOVA and Tukey's post hoc tests for individual means. A two-sided $p$ value $<0.05$ was considered significant. All analyses were conducted using SAS version 9.1 (SAS Institute).

\section{Results}

\section{RPE65 is localized within the OS of human green/red cones}

To investigate whether RPE65 is localized within human cones, two polyclonal antibodies raised against distinct epitopes of RPE65 were used that have been shown previously to exhibit high specificity in mouse (Redmond and Hamel, 2000; Tang et al., 2011) and chicken (Moiseyev et al., 2008) (see Table 1). We evaluated the specificities of both antibodies for human RPE65 in the RPE because this is the region of the eye in which the protein is widely accepted to be localized and to function. The RPE was obtained from donor eyes and homogenized for immunoblotting. We found that both antibodies detected a $\sim 63 \mathrm{kDa}$ major band in RPE homogenates corresponding to the known size of the protein (Fig. $2 A$ ). Frozen sections of dissected RPE were used for IHC staining, and both antibodies showed robust staining within the RPE (Fig. $2 B$ ). These results confirmed the high specificity of the antibodies for human RPE65.

To determine whether RPE65 immunostaining was localized in rods or cones, we costained human eyecup sections for RPE65 and either rhodopsin or cone arrestin and found that RPE65 was present only in cones (Fig. $3 A-C$ ). Results from staining with both anti-RPE65 antibodies confirmed that this is not specific to a single antibody (Fig. 2C). Because the Müller glia has been implicated to synthesize 11-cis-ROL as part of the alternate visual cycle, the presence of RPE65 within this cell type was also evaluated. Costaining for RPE65 and glutamine synthetase, a glial marker, showed a lack of colocalization, indicating that RPE65 was absent from the Müller glia (Fig. 3D). 

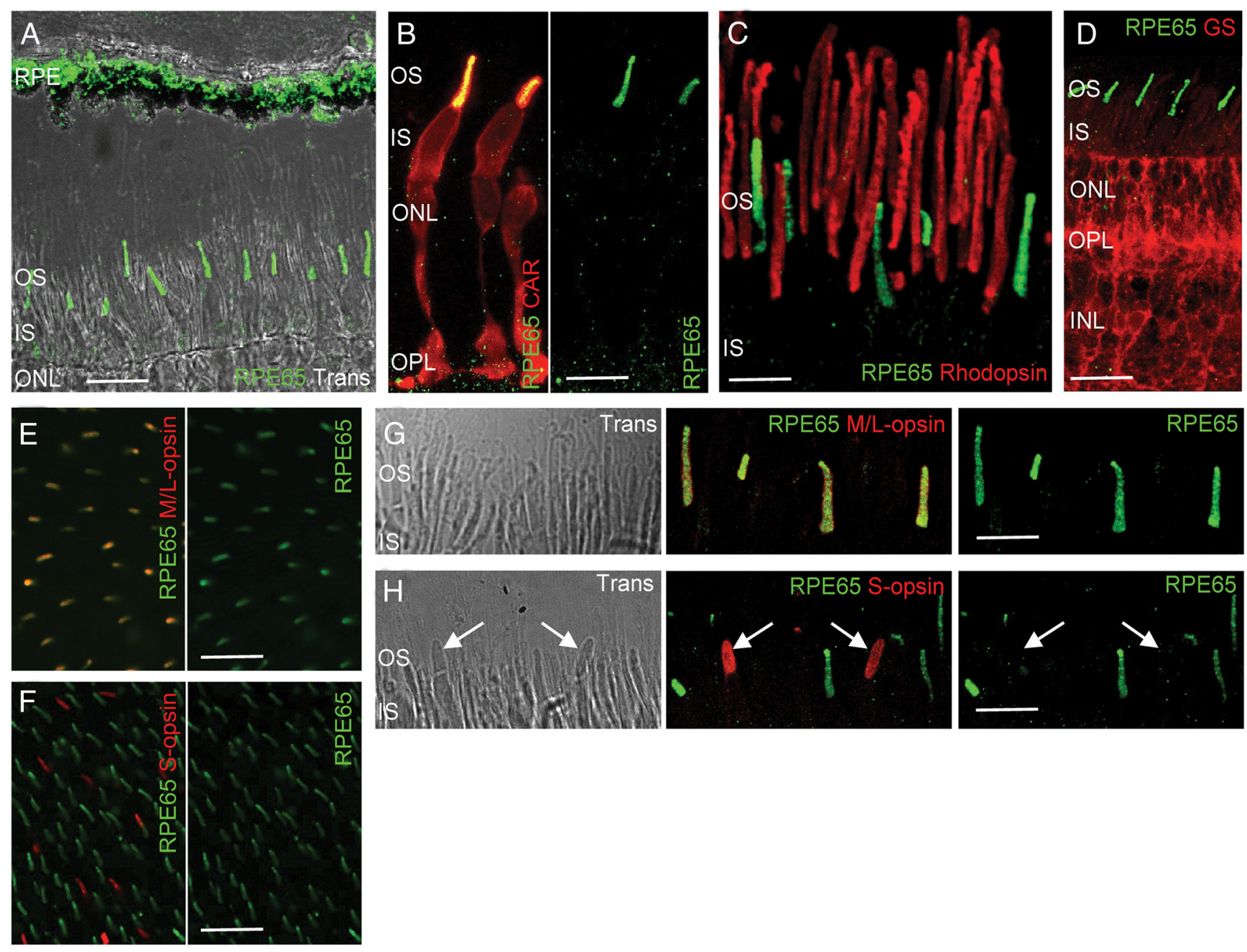

Figure 3. RPE65 is detected within human green/red cone $0 S$. Images are acquired from sections prepared from a young donor eye (age 11 years). Morphologic analysis indicates that RPE65 is present in both the RPE and OS layers of the retina $(\boldsymbol{A})$. Costaining with cone arrestin (CAR), rhodopsin, or glutamine synthetase (GS) shows that RPE65 is localized within the cone 0S (B) but absent from rods $(\boldsymbol{C})$ and the Müller glia $(\boldsymbol{D})$. Pieces of the retina were flat mounted $(\boldsymbol{E}, \boldsymbol{F})$ or sectioned $(\boldsymbol{G}, \boldsymbol{H})$ and costained for RPE65 and either M/L-opsin or S-opsin, showing presence of RPE65 in green/red cones $(\boldsymbol{E}, \boldsymbol{G})$ but not in blue cones $(\boldsymbol{F}, \boldsymbol{H})$. INL, Inner nuclear layer; IPL, inner plexiform layer; ONL, outer nuclear layer; OPL, outer plexiform layer; Trans, transmitted light. Scale bars: $\boldsymbol{A}, \boldsymbol{D}$, $20 \mu \mathrm{m} ; \boldsymbol{B}, \boldsymbol{H}, 10 \mu \mathrm{m} ; \boldsymbol{C}, 5 \mu \mathrm{m} ; \boldsymbol{G}, 7 \mu \mathrm{m} ; \boldsymbol{E}, \boldsymbol{F}, 40 \mu \mathrm{m}$. White arrows in $\boldsymbol{H}$ indicate the presence of blue cone $0 S$.

A
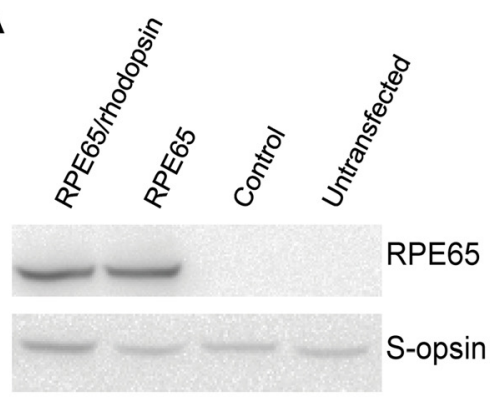

$M / L-o p \sin$

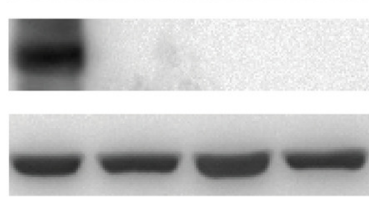

B
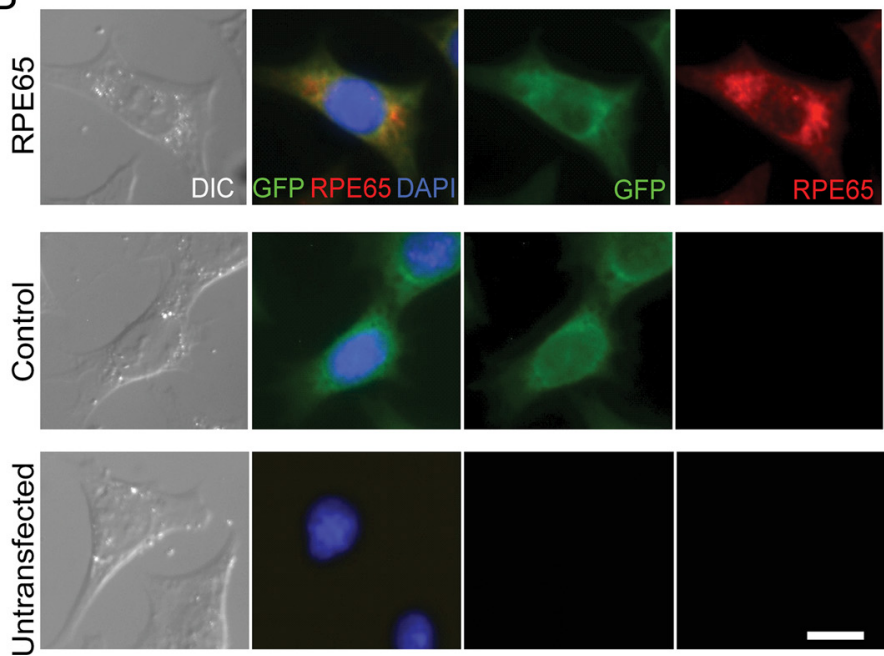

Figure 4. $661 \mathrm{~W}$ cells are genetically modified to express RPE65. Immunoblot analysis is used to confirm the expression of various proteins in different groups of $661 \mathrm{~W}$ cells (A). Expression of RPE65 is confirmed through IHC (B). DIC, Differential interference contrast. Scale bar, $2 \mu \mathrm{m}$. 
We noticed a few cones stained for cone arrestin but not for RPE65 in our previous preparation, prompting additional studies to determine whether RPE65 was expressed uniformly among the three different subtypes of human cones. Using opsin-specific antibodies for IHC, we were not able to discriminate between green and red cones because the antibody detects both $\mathrm{M}$ - and L-opsins; however, we were able to discriminate blue cones. Human retinas were costained for RPE65 and either M/L- or S-opsin, flat mounted onto a slide, and analyzed. We found that RPE65 immunostaining localized to the OS of green/red cones but was absent from blue cones (Fig. $3 E, F$ ). IHC analysis of frozen sections confirmed these findings (Fig. 3G,H), suggesting that human blue cones do not express RPE65. Our data were collected from the peripheral human retina because we lacked wellpreserved foveal samples for analysis; however, we believe these findings are applicable to foveal cones because their normal function in bright light warrants high photopigment turnover. We conclude that RPE65 is present within human cones and that there is a selective expression of the protein among the different cone subtypes.

\section{$661 \mathrm{~W}$ cells are modified to express RPE65}

To evaluate the possible mechanism by which cone RPE65 supports photopigment synthesis, we used an in vitro cone cell model based on the $661 \mathrm{~W}$ cell. This cell line is of mouse origin and demonstrates numerous cellular and biochemical characteristics of cones, including the expression of both types of mouse cone opsins ( $\mathrm{M}$ and $\mathrm{S}$ ), transducin, and arrestin; however, RPE65 is absent (Tan et al., 2004; Kanan et al., 2008). A monoclonal population of stable RPE65-expressing 661W cells was generated through transfection with a plasmid construct containing cassettes encoding for mouse RPE65 and GFP as a reporter. For control, the plasmid devoid of Rpe 65 cDNA was used. Successful expression of RPE65 in transfected $661 \mathrm{~W}$ cells was verified through immunoblotting and IHC (Fig. 4).

\section{RPE65 does not mediate an isomerase activity in cones in vitro}

Previous studies have shown that $661 \mathrm{~W}$ cells possess an unidentified mechanism for generating RE (presumably the all-trans isoform) from all-trans-ROL that is independent of lecithin retinol acyltransferase or acyl CoA retinol acyltransferase (Kanan et al., 2008), the two enzymes catalyzing retinoid esterification in the RPE and alternate visual cycles, respectively. Because alltrans-RE has been established as the substrate for the RPE65mediated isomerase reaction to generate 11-cis-ROL within the RPE (Moiseyev et al., 2003), our initial studies were to determine
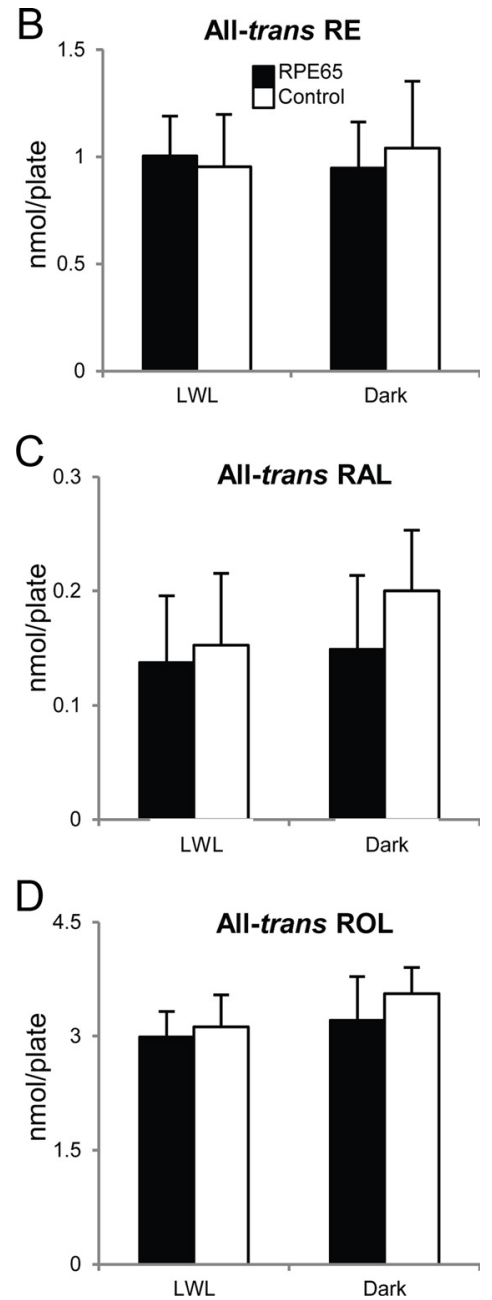

Retention Time ( $\mathrm{min})$

Figure 5. RPE65 does not mediate an isomerase activity within 661W cells. Rpe65-transfected and control 661W cells were incubated changes among the three forms of retinoids detected ( $\boldsymbol{B}-\boldsymbol{D}$; left). 11-cis-Retinoids (RE, ROL, or RAL) were not detected in either group of cells, suggesting the lack of an isomerase activity. $n=7$ for each condition. Error bars represent SD.

whether RPE65 would mediate a similar activity with endogenously synthesized all-trans-RE in $661 \mathrm{~W}$ cells. After $24 \mathrm{~h}$ of incubation in the dark with media containing $10 \mu \mathrm{M}$ all-trans-ROL, retinoids were extracted from cells and analyzed using HPLC. Rpe65-transfected and control 661W cells appeared to synthesize similar amounts of all-trans-RE (Fig. 5B). Only all-transretinoids (RE, ROL, or RAL) were detected in these cells (Fig. 5A) or in the incubation media (Fig. 6A), but 11-cis-retinoids were not observed.

A possible explanation for the lack of 11-cis-retinoid synthesis in Rpe65-transfected 661W cells could be the absence of photopigment bleaching to drive the isomerase reaction. Thus, to simultaneously bleach photopigments while preserving endogenous retinoids within the cells, we used a long-wavelength light ( $\mathrm{LWL} ; \geq 500 \mathrm{~nm}$; 1000 lux) to bleach M-opsin photopigments. If the RPE65mediated isomerase activity were to be driven by this process, a decrease in the amount of all-trans-RE (used for 11-cis-RAL synthesis) and/or an increase in the amount of all-trans-RAL (result of photopigment bleaching) would be expected. Cells were incu- 
A

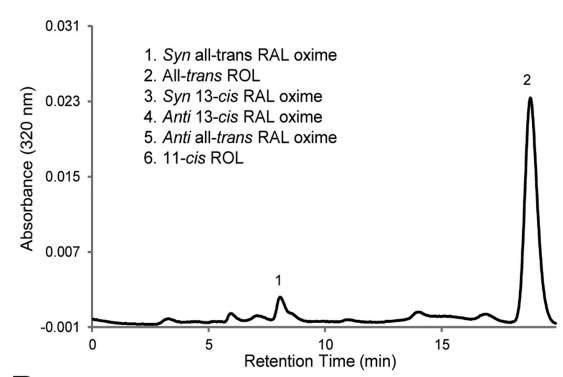

B

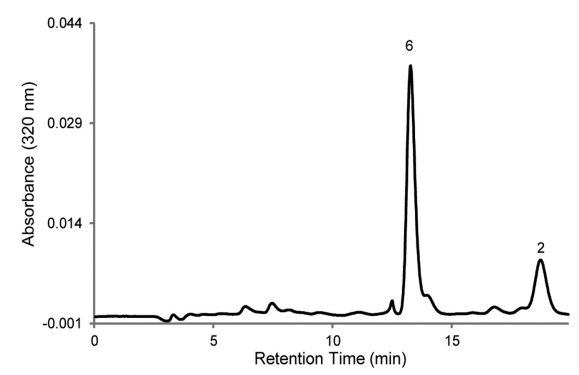

All-trans ROL Incubation Media
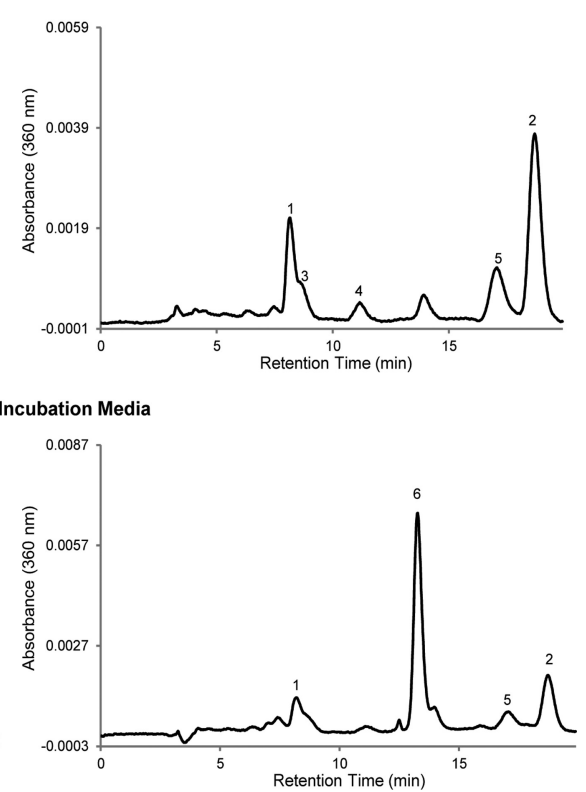

Figure 6. Retinoid profiles of incubation media. Rpe65-transfected $661 \mathrm{~W}$ cells were incubated in media that was loaded with $10 \mu \mathrm{m}$ either all-trans-ROL or 11-cis-ROL for $24 \mathrm{~h}$. After the incubation period, retinoids were extracted from the media and analyzed by HPLC. All-trans-retinoids were detected in all-trans-ROL-loaded media after incubation; however, 11-cis-retinoids were absent $(\boldsymbol{A})$. BSA served as an adequate carrier and maintained a significant amount of 11-cis-ROL in the incubation media after $24 \mathrm{~h}(\boldsymbol{B})$.

bated with all-trans-ROL as described previously, washed thoroughly, incubated in retinoid-free media, and exposed for 5 min to LWL. We found no significant changes in the amounts of all-trans-RE or all-trans-RAL after Rpe65-transfected 661W cells were bleached (Fig. $5 B, C$ ), suggesting that the isomerase function classically attributed to RPE65 in the RPE is not present in our in vitro cone cell model.

\section{RPE65 mediates an ester hydrolase activity in cones in vitro}

Because cones have been shown to generate chromophore from 11-cis-ROL synthesized by the Müller glia as part of the alternate visual cycle (Parker et al., 2011), we incubated our cells in media containing 11-cis-ROL (10 $\mu \mathrm{M})$ under similar conditions as described above. BSA served as an adequate carrier and maintained a significant proportion of 11-cis-ROL in the incubation media after 24 h; however, a minute amount of all-trans-ROL was detected, presumably generated from the thermoisomerization of 11-cis-ROL (Fig. 6B). Similar amounts of 11-cis-REs and alltrans-REs were detected in both Rpe65-transfected and control $661 \mathrm{~W}$ cells (Fig. $7 \mathrm{~B}, \mathrm{C}$ ). Interestingly, the amount of 11-cis-RE produced from incubation with 11-cis-ROL was twofold greater than the amount of all-trans-RE produced from incubation with all-trans-ROL across all groups tested. These data suggest that the unidentified esterification activity within $661 \mathrm{~W}$ cells is more efficient with 11-cis-ROL as a substrate than with all-trans-ROL.

Whereas 11-cis-ROL was detected in Rpe65-transfected 661W cells, possibly as a result of the inadequate washing away of incubation media, 11-cis-RAL was absent. Again, we considered the possibility that photopigment bleaching could drive chromophore synthesis in this model system. Rpe65-transfected and control 661W cells were incubated with 11-cis-ROL for $24 \mathrm{~h}$ in the dark, washed thoroughly, incubated in retinoid-free media, and bleached with LWL for $5 \mathrm{~min}$. We observed that LWL bleaching of Rpe65-transfected cells caused a decrease in 11-cis-RE $(\sim 0.93 \mathrm{nmol} /$

plate; Fig. $7 B$ ) proportional to an increase in the amount of all-trans-RAL detected $(\sim 0.87 \mathrm{nmol} /$ plate; Fig. $7 F)$. No significant differences in the amount of 11-cis-RE or all-trans-RAL were observed when control 661W cells were similarly bleached (Fig. $7 B, F)$. These data suggest that photopigment bleaching triggers RPE65 to mobilize 11-cis-RE for chromophore production, possibly through mediating the hydrolysis of the ester bond to release 11-cis-ROL for oxidation.

\section{Oxidation of 11-cis-ROL occurs within 661W cells}

Although our data show that bleaching Rpe65-transfected 661W cells with LWL drives the utilization of 11-cis-RE to regenerate photopigment, we had thus far been unable to detect 11-cis-RAL in retinoids extracted from these cells. This could be explained by the unstable nature of the cone photopigment, which has a much higher tendency to spontaneously dissociate into 11-cis-RAL and the apoopsin protein when compared with the more stable rod photopigment (Matsumoto et al., 1975; Kefalov et al., 2005), allowing for degradation of the chromophore to take place. Therefore, Rpe65-transfected $661 \mathrm{~W}$ cells were secondarily transfected to express rhodopsin (RPE65/rhodopsin) (Fig. 4A) so that the rod opsin could serve as a sink for capturing and maintaining any 11-cis-RAL that may be generated. We observed detectable amounts of 11-cis-RAL in RPE65/ rhodopsin-transfected cells after incubation with 11-cis-ROL for $24 \mathrm{~h}$ in the dark, but none was detected when cells were incubated with all-trans-ROL (Fig. 8). These results confirm the synthesis of 11-cis-RAL in 661W cells expressing RPE65 and are the first to show the existence of an 11-cis-ROL oxidase activity within this mouse cone cell line. Additional support for the existence of the oxidase activity comes from the similar profiles of known photoreceptor RDHs expressed by both $661 \mathrm{~W}$ cells and cones of the neural retina leucine zipper knock-out $\left(\mathrm{Nrl}^{-/-}\right)$mouse (Kanan et al., 2008), which have also been suggested to possess an 11-cisROL oxidase activity (Parker et al., 2011). Additional studies are necessary to determine whether this oxidase activity is mediated by a novel RDH or by a previously uncharacterized function of a known RDH.

\section{Discussion}

\section{RE synthesis in cones}

The isomerase of the alternate visual cycle is believed to exist within the Müller glia to catalyze a direct all-trans- to 11-cis-ROL conversion (Das et al., 1992; Mata et al., 2002, 2005; Wang and Kefalov, 2011), in which 11-cis-ROL is subsequently shuttled to cones to produce 11-cis-RAL. Our current results from the $661 \mathrm{~W}$ cell line indicate that the existence of an intermediate esterase synthesis step is crucial for the cone to synthesis 11-cis-RAL from incoming 11-cis-ROL. 11-cis-RE synthesis in the cone could serve a similar storage role as observed with all-trans-RE synthesis in the RPE, in which a readily available pool of substrate is essential for the production of chromophore to meet functional demands. Cones can use 11-cis-ROL for photopigment formation (Jones et 
A
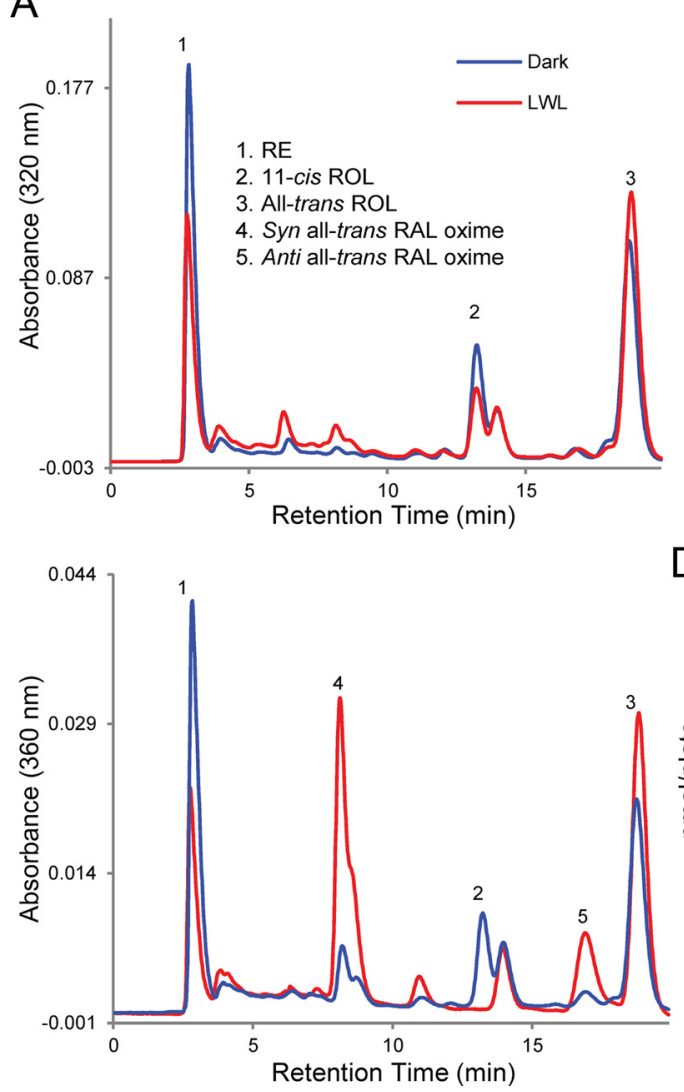
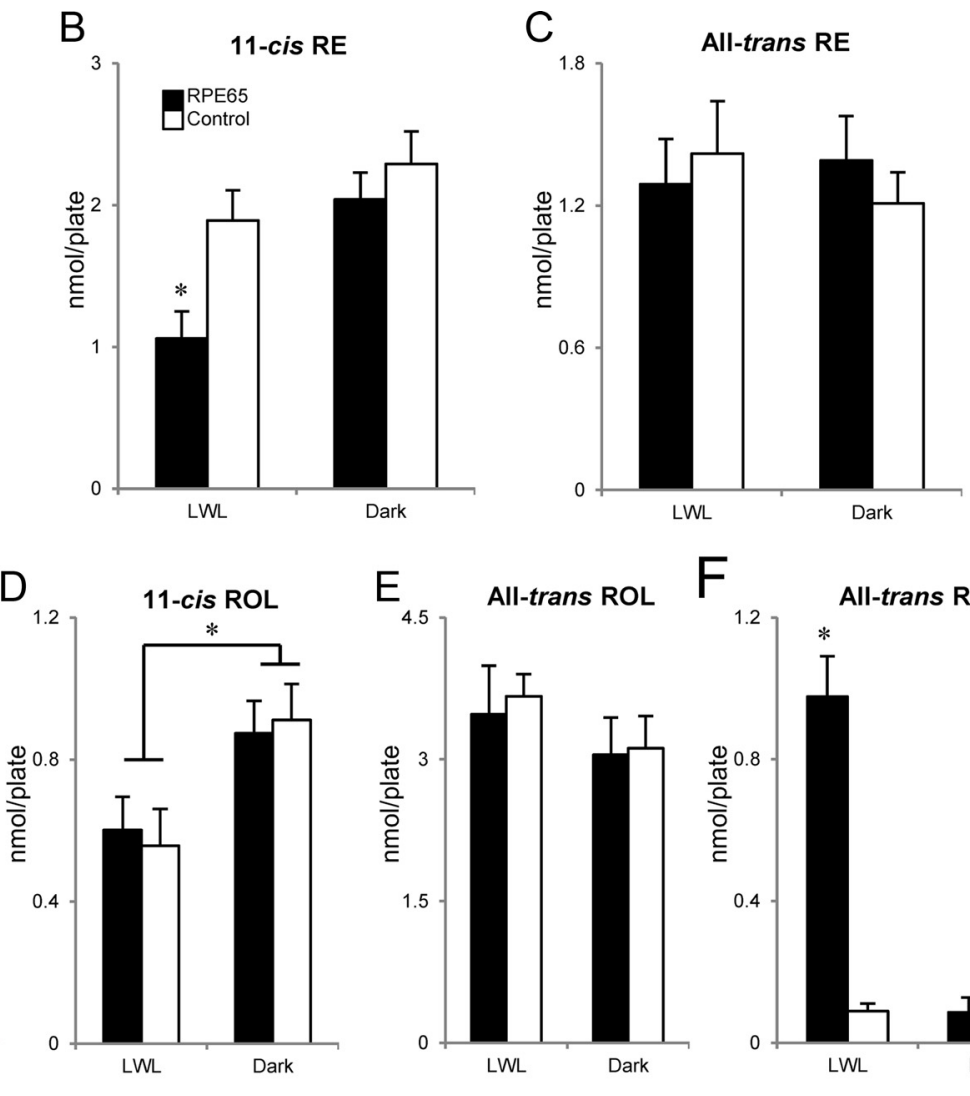

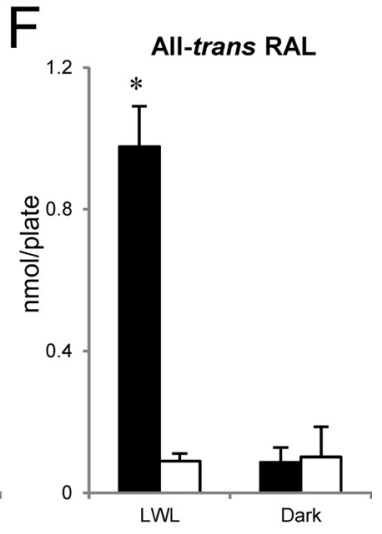

Figure 7. RPE65 may mediate an ester hydrolase activity within 661W cells. Rpe65-transfected and control 661W cells were incubated with $10 \mu \mathrm{m} 11$-cis-R0L and analyzed as described previously for Figure 4. Chromatographs at $320 \mathrm{~nm}$ (top) and $360 \mathrm{~nm}$ (bottom) absorbance are shown for retinoids extracted from dark-reared (blue) or LWL-bleached (red) Rpe65-transfected 661W cells (A). There was no significant ( $p>0.05$ ) difference observed in the quantities of 11-cis-RE ( $\boldsymbol{B}$, right) or all-trans-RE (C, right) between dark-reared Rpe65-transfected and control 661W cells; however, the quantity of 11-cis-RE (RPE65, 2.04 \pm $0.19 \mathrm{nmol} /$ plate; control, $2.29 \pm 0.23 \mathrm{nmol} /$ plate) was observed to be approximately twofold greater than the quantity of all-trans-RE detected (RPE65, $1.39 \pm 0.17 \mathrm{nmol} /$ plate; control, $1.21 \pm 0.13$ $\mathrm{nmol} /$ plate) in corresponding groups. There was no significant $(p>0.05)$ differences observed in the quantities of 11 -cis-ROL $(\boldsymbol{D}$, right), all-trans-ROL $(\boldsymbol{E}$, right), or all-trans-RAL $(\boldsymbol{F}$, right) between dark-reared Rpe65-transfected and control cells. Bleaching Rpe65-transfected 661W cells with LWL resulted in a significant $(p<0.01)$ decrease in the quantity of 11 -cis-RE (1.06 $\pm 0.19 \mathrm{nmol} / \mathrm{plate})(\boldsymbol{B}$, left) that corresponded to a significant $(p<0.001)$ increase in the quantity of all-trans-RAL $(0.98 \pm 0.11 \mathrm{nmol} /$ plate) compared with control cells $(11-$ cis-RE, $1.89 \pm 0.21 \mathrm{nmol} / \mathrm{plate}$; all-trans-RAL, $0.09 \pm 0.02 \mathrm{nmol} / \mathrm{plate})(\boldsymbol{F}$, left). No significant $(p>0.05)$ differences were observed in the quantities of all-trans-ROL ( $\boldsymbol{E}$, left) or 11-cis-ROL ( $\boldsymbol{D}$, left) between the two groups of cells after LWL bleaching; however, the quantities of 11 -cis-R0L in both groups of cells were significantly $(p<0.01)$ reduced compared with corresponding groups that were dark-reared $\left(\boldsymbol{D}\right.$, right). $n=8$ for each condition. Error bars represent SD. ${ }^{*}$ indicates significance.

al., 1989; Parker et al., 2011), presumably through a novel oxidase activity. This may underlie the specificity of the alternate visual cycle for cones because rods appear to lack the oxidase and cannot use 11-cisROL for chromophore synthesis (Kono et al., 2008; Ala-Laurila et al., 2009).

\section{RPE65 function in cones}

The role of RPE65 in retinoid metabolism has been characterized extensively within the RPE; however, its role within cones has not been studied (Wang and Kefalov, 2011). Processes from the Müller glia make numerous associations with the cone cell body (Uehara et al., 1990), and 11-cisROL is thought to be delivered to this region of the cell (Wang et al., 2009). We hypothesize that RPE65 could be performing three roles within cones. First, 11-cis-ROL may be esterified within the cone cell body and/or IS and RPE65-mediated ester hydrolysis is occurring at the OS interface, possibly at the connecting cilium (CC), thus explaining why the protein is localized
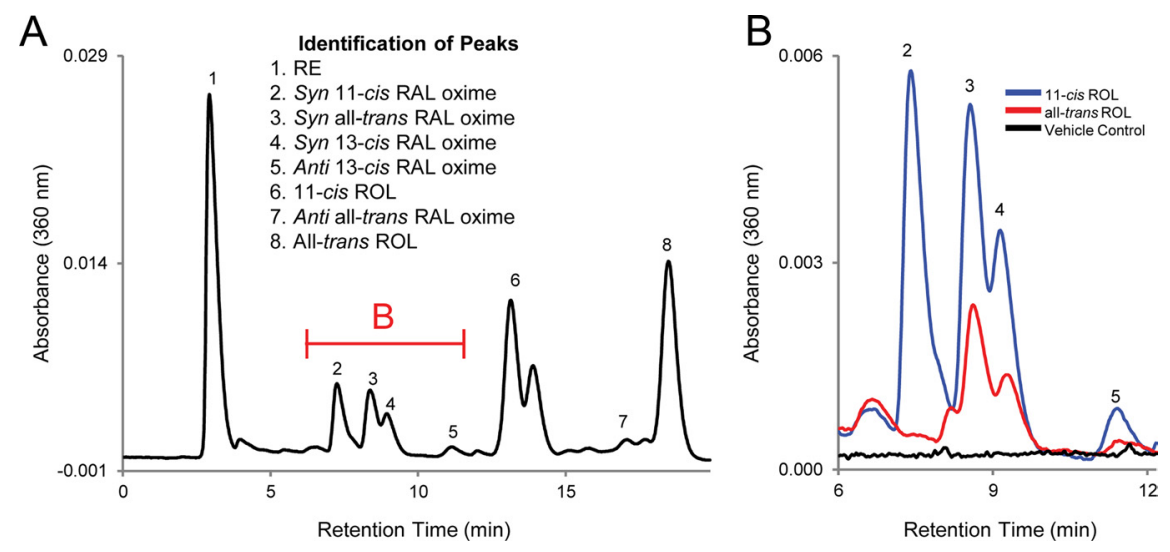

Figure 8. 11-cis-RAL synthesis is detected in RPE65/rhodopsin-transfected 661W cells. RPE65/rhodopsin-transfected 661W cells were incubated with $10 \mu \mathrm{M}$ 11-cis-ROL, all-trans-ROL, or vehicle for $24 \mathrm{~h}$ in dark conditions. Representative HPLC chromatograph of extracted retinoids from cells incubated with 11-cis-ROL $(\boldsymbol{A})$. The indicated portion of the chromatograph is expanded in $\boldsymbol{B}$ and displayed for cells incubated with 11-cis-ROL (blue), all-trans-ROL (red), or vehicle (black). Presence of 11-cis-RAL is only detected in cells incubated with 11-cis-ROL.

densely in this region of the mouse cone (Tang et al., 2011). Second, RPE65 may act as a retinoid binding protein (RBP) to stabilize 11cis-ROL and to shuttle it along the OS. Evidence for this comes from the punctate appearance of RPE65 immunostaining in the apical 
regions of the mouse cone OS (Tang et al., 2011) and the recent discovery that the actin-based motor protein myosin VIIa (MYO7A) mediates translocation of RPE65 within the mouse RPE (Lopes et al., 2011). MYO7A may be involved in trafficking RPE65 within the cone because MYO7A has been localized robustly at the CC region of human and rodent photoreceptors (Liu et al., 1997) and is required for the normal trafficking of opsins through the ciliary plasma membrane to the OS (Liu et al., 1999). Finally, the possible RBP role of RPE65 may enhance 11-cis-ROL oxidation, increasing the probability of the retinoid for interacting with RDHs (Hemati et al., 2005; Kiser et al., 2009). The current results from the in vitro cone cell model may explain why mouse strains with a higher abundance of cone RPE65 were more efficient at synthesizing cone photopigments than those with a lower abundance of the protein (Tang et al., 2011). Additional studies using subcellular imaging techniques, such as immunoelectron microscopy, and further characterization of the unidentified 11-cis-ROL oxidase activity are essential for clarifying the mechanism of cone RPE65.

\section{RPE65 expression in human cone subtypes}

This study is the first to establish the relevance of cone RPE65 for human vision because we have shown that the protein is localized to the OS of human cones (Fig. 3). Surprisingly, RPE65 was detected in green/red cones but not in blue cones, suggesting that green/red cones have privileged access to an additional pool of retinoids for chromophore synthesis, whereas blue cones rely solely on the RPE.

Can the absence of RPE65 expression in human blue cones be related to human diurnal vision being more dependent on green and red cones than on blue cones? A large proportion of short-wavelength light that the eye receives from the surrounding environment is filtered out by the cornea and lens before reaching the retina (Boettner and Wolter, 1962), diminishing the contribution of blue cones for human vision. Furthermore, a recent study in mice suggested that full recovery of mouse cone photopigments was biphasic, with the alternate visual cycle mediating the initial fast phase and the slower RPE visual cycle completing the process (Kolesnikov et al., 2011). Blue cones compose $<6 \%$ of the total primate cone population (Roorda et al., 2001) and are absent from the fovea of the human retina (Curcio et al., 1991), a pure-cone region in which fast cone photopigment regeneration is essential to mediate central vision in bright light. It is possible that both visual cycles (RPE and alternate) supply human green/red cones with chromophore to support rapid photopigment regeneration for central vision, but the less essential blue cone can only access the slower RPE visual cycle.

\section{Implications on the therapeutic strategy for LCA2}

The results from this study may compel clinicians to reconsider the tissue targets of gene therapy in the attempt to rescue and preserve diurnal vision in LCA2 patients. The current strategy focuses on restoration of functional RPE65 in the RPE, based on the widely accepted belief that the protein exists and functions exclusively within this region of the eye. Can the efficacy of this powerful therapeutic method be enhanced if cones were also targeted for restoration? Our results show that RPE65 is indeed present within human cones and offer an initial explanation for its contribution to photopigment synthesis. Additional investigation of the role of RPE65 within the cone in vivo will lead to a better understanding of the pathogenesis of LCA2 and improve the therapies that we can offer to patients who suffer from this devastating eye disease.

\section{References}

Ala-Laurila P, Cornwall MC, Crouch RK, Kono M (2009) The action of 11-cis retinol on cone opsins and intact cone photoreceptors. J Biol Chem 284:16492-16500.

Boettner E, Wolter J (1962) Transmission of the ocular media. Invest Ophthalmol Vis Sci 1:776-783.

Cideciyan AV (2010) Leber congenital amaurosis due to RPE65 mutations and its treatment with gene therapy. Prog Retin Eye Res 29:398-427.

Curcio CA, Allen KA, Sloan KR, Lerea CL, Hurley JB, Klock IB, Milam AH (1991) Distribution and morphology of human cone photoreceptors stained with anti-blue opsin. J Comp Neurol 312:610-624.

Das SR, Bhardwaj N, Kjeldbye H, Gouras P (1992) Muller cells of chicken retina synthesize 11-cis-retinol. Biochem J 285:907-913.

den Hollander AI, Roepman R, Koenekoop RK, Cremers FP (2008) Leber congenital amaurosis: genes, proteins and disease mechanisms. Prog Retin Eye Res 27:391-419.

Groenendijk GW, De Grip WJ, Daemen FJ (1980) Quantitative determination of retinals with complete retention of their geometric configuration. Biochim Biophys Acta 617:430-438.

Hemati N, Feathers KL, Chrispell JD, Reed DM, Carlson TJ, Thompson DA (2005) RPE65 surface epitopes, protein interactions, and expression in rod- and cone-dominant species. Mol Vis 11:1151-1165.

Jin M, Li S, Moghrabi WN, Sun H, Travis GH (2005) Rpe65 is the retinoid isomerase in bovine retinal pigment epithelium. Cell 122:449-459.

Jones GJ, Crouch RK, Wiggert B, Cornwall MC, Chader GJ (1989) Retinoid requirements for recovery of sensitivity after visual-pigment bleaching in isolated photoreceptors. Proc Natl Acad Sci U S A 86:9606-9610.

Kanan Y, Kasus-Jacobi A, Moiseyev G, Sawyer K, Ma JX, Al-Ubaidi MR (2008) Retinoid processing in cone and Müller cell lines. Exp Eye Res 86:344-354.

Kefalov VJ, Estevez ME, Kono M, Goletz PW, Crouch RK, Cornwall MC, Yau KW (2005) Breaking the covalent bond-a pigment property that contributes to desensitization in cones. Neuron 46:879-890.

Kiser PD, Golczak M, Lodowski DT, Chance MR, Palczewski K (2009) Crystal structure of native RPE65, the retinoid isomerase of the visual cycle. Proc Natl Acad Sci U S A 106:17325-17330.

Kolesnikov AV, Tang PH, Parker RO, Crouch RK, Kefalov VJ (2011) The mammalian cone visual cycle promotes rapid M/L-cone pigment regeneration independently of the interphotoreceptor retinoid-binding protein. J Neurosci 31:7900-7909.

Kono M, Goletz PW, Crouch RK (2008) 11-cis and all-trans retinols can activate rod opsin: rational design of the visual cycle. Biochemistry 47:7567-7571.

Liu X, Vansant G, Udovichenko IP, Wolfrum U, Williams DS (1997) Myosin VIIa, the product of the Usher 1B syndrome gene, is concentrated in the connecting cilia of photoreceptor cells. Cell Motil Cytoskeleton $37: 240-252$.

Liu X, Udovichenko IP, Brown SD, Steel KP, Williams DS (1999) Myosin VIIa participates in opsin transport through the photoreceptor cilium. J Neurosci 19:6267-6274.

Lopes VS, Gibbs D, Libby RT, Aleman TS, Welch DL, Lillo C, Jacobson SG, Radu RA, Steel KP, Williams DS (2011) The Usher 1B protein, MYO7A, is required for normal localization and function of the visual retinoid cycle enzyme, RPE65. Hum Mol Genet 20:2560-2570.

Ma J, Xu L, Othersen DK, Redmond TM, Crouch RK (1998) Cloning and localization of RPE65 mRNA in salamander cone photoreceptor cells. Biochim Biophys Acta 1443:255-261.

Mata NL, Radu RA, Clemmons RC, Travis GH (2002) Isomerization and oxidation of vitamin A in cone-dominant retinas: a novel pathway for visual-pigment regeneration in daylight. Neuron 36:69-80.

Mata NL, Ruiz A, Radu RA, Bui TV, Travis GH (2005) Chicken retinas contain a retinoid isomerase activity that catalyzes the direct conversion of all-trans retinol to 11-cis retinol. Biochemistry 44:11715-11721.

Matsumoto H, Tokunaga F, Yoshizawa T (1975) Accessibility of the iodopsin chromophore. Biochim Biophys Acta 404:300-308.

Moiseyev G, Crouch RK, Goletz P, Oatis J Jr, Redmond TM, Ma JX (2003) Retinyl esters are the substrate for isomerohydrolase. Biochemistry 42:2229-2238. 
Moiseyev G, Chen Y, Takahashi Y, Wu BX, Ma JX (2005) RPE65 is the isomerohydrolase in the retinoid visual cycle. Proc Natl Acad Sci U S A 102:12413-12418.

Moiseyev G, Takahashi Y, Chen Y, Kim S, Ma JX (2008) RPE65 from conedominant chicken is a more efficient isomerohydrolase compared with that from rod-dominant species. J Biol Chem 283:8110-8117.

Muniz A, Betts BS, Trevino AR, Buddavarapu K, Roman R, Ma JX, Tsin AT (2009) Evidence for two retinoid cycles in the cone-dominant chicken eye. Biochemistry 48:6854-6863.

Parker R, Wang JS, Kefalov VJ, Crouch RK (2011) IRBP is the physioloigcally relevant carrier of 11-cis retinol in the cone visual cycle. J Neurosci 31:4714-4719.

Redmond TM, Hamel CP (2000) Genetic analysis of RPE65: from human disease to mouse model. Methods Enzymol 316:705-724.

Redmond TM, Yu S, Lee E, Bok D, Hamasaki D, Chen N, Goletz P, Ma JX, Crouch RK, Pfeifer K (1998) RPE65 is necessary for production of 11cis-vitamin A in the retinal visual cycle. Nat Genet 20:344-351.

Redmond TM, Poliakov E, Yu S, Tsai JY, Lu Z, Gentleman S (2005) Mutation of key residues of Rpe65 abolishes its enzymatic role as isomerohydrolase in the visual cycle. Proc Natl Acad Sci U S A 102:13658-13663.

Roorda A, Metha AB, Lennie P, Williams DR (2001) Packing arrangement of the three cone classes in primate retina. Vision Res 41:1291-1306.

Saari JC, Bredberg DL, Farrell DF (1993) Retinol esterification in bovine retinal pigment epithelium: reversibility of lecithin:retinol acyltransferase. Biochem J 291:697-700.

Tan E, Ding XQ, Saadi A, Agarwal N, Naash MI, Al-Ubaidi MR (2004) Expression of cone-photoreceptor-specific antigens in a cell line derived from retinal tumors in transgenic mice. Invest Ophthalmol Vis Sci 45:764-768.

Tang PH, Wheless L, Crouch RK (2011) Regeneration of photopigment is enhanced in mouse cone photoreceptors expressing RPE65 protein. J Neurosci 31:10403-10411.

Travis GH, Golczak M, Moise AR, Palczewski K (2007) Diseases caused by defects in the visual cycle: retinoids as potential therapeutic agents. Annu Rev Pharmocol Toxicol 47:469-512.

Uehara F, Matthes MT, Yasumura D, LaVail MM (1990) Light-evoked changes in the interphotoreceptor matrix. Science 248:1633-1636.

Wang JS, Kefalov VJ (2009) An alternative pathway mediates the mouse and human cone visual cycle. Curr Biol 19:1665-1669.

Wang JS, Kefalov VJ (2011) The cone-specific visual cycle. Prog Retin Eye Res 30:115-128.

Wang JS, Estevez ME, Cornwall MC, Kefalov VJ (2009) Intra-retinal visual cycle required for rapid and complete cone dark adaptation. Nat Neurosci 12:295-302.

Zhang H, Cuenca N, Ivanova T, Church-Kopish J, Frederick JM, MacLeish PR, Baehr W (2003) Identification and light-dependent translocation of a cone-specific antigen, cone arrestin, recognized by monoclonal antibody 7G6. Invest Ophthalmol Vis Sci 44:2858-2867.

Znoiko SL, Crouch RK, Moiseyev G, Ma JX (2002) Identification of the RPE65 protein in mammalian cone photoreceptors. Invest Ophthalmol Vis Sci 43:1604-1609.

Znoiko SL, Rohrer B, Lu K, Lohr HR, Crouch RK, Ma JX (2005) Downregulation of cone-specific gene expression and degeneration of cone photoreceptors in the RPE65 ${ }^{-1-}$ mouse at early ages. Invest Ophthalmol Vis Sci 46:1473-1479. 